\title{
Dossiê Olhares sobre a Escola: representações da escola no cinema
}

\author{
César Cundari ${ }^{1}$ \\ Lennita Oliveira Ruggi ${ }^{2}$ \\ Marcelo Francisco ${ }^{3}$
}

Uma das características mais salientes dos discursos que constituem a educação na atualidade é a mania de imaginar escola e mídia como entidades concorrentes e contrastantes, competindo na formação das crianças e jovens. Abordagens apocalípticas dão amplos poderes à mídia como uma totalidade coerente, inteiramente engajada na promoção do consumo capitalista e, por esse motivo mesmo, incapaz de respeitar valores pretensamente humanos que seriam indispensáveis no processo educacional. A escola seria uma das últimas divisórias impedindo a ruína da sociedade no egoísmo superficial centrado na aparência e distanciado do "saber".

$\mathrm{Na}$ margem oposta, enunciados integrados à necessidade de transformação alardeiam com fascínio ambíguo o crescente poder das mídias na constituição das subjetividades, na proliferação de

${ }^{1}$ Graduado em História na Universidade Federal do Paraná e pós-graduado pela Pontifícia Universidade Católica do Paraná, email: cesar_ocundari@ yahoo.com.br ${ }^{2}$ Professora de Sociologia da Educação na Universidade Federal do Paraná, email: lennitaruggi@hotmail.com

${ }^{3}$ Graduado em Ciências Sociais pela Universidade Federal do Paraná, email: marcelosociais@gmail.com 
identidades e multiplicação das possibilidades de comunicação tanto de si como de demandas dos movimentos sociais. Frente às inovações tecnológicas, a escola teria perdido o passo na coreografia do progresso e as receitas para sua reabilitação povoam com sucesso o mercado pedagógico, sendo a inserção consciente ou a exclusão irrevogável das tecnologias no contexto escolar alguns dos antídotos mais recomendados.

Nesse panorama um tanto viciado, debater mídia e educação quase sempre exige integrar uma das torcidas ou, com mais frequência ainda, manter uma postura pretensamente imparcial com pompons na mão direita e pedras na esquerda para oferecê-los conforme a ocasião. Tentar atravessar esse campo curricular minado com ambas as mãos ocupadas é, no mínimo, desconfortável. Foi esse incômodo que deu origem ao Grupo de Pesquisa Olhares sobre a Escola: a educação nos discursos de entretenimento, em atividade desde 2011 na Universidade Federal do Paraná, cuja ambição é procurar um plug diferente para aproximar escola e mídia, uma abordagem que confunda as fronteiras para oferecer um panorama com menos arestas e mais áreas de contato. Nosso objetivo é investigar os discursos produzidos a respeito da escola pela mídia de entretenimento. Alguns exemplos significativos podem explicitar o enfoque.

A expressão “E o salário: óóóóóó....", acompanhada por um gesto com polegar e indicador da mão esquerda para indicar 
insignificância, característica do personagem Raimundo Nonato, de Chico Anysio, era o encerramento tradicional do programa Escolinha do Professor Raimundo da TV Globo. Entre as pessoas que residiram no Brasil durante as últimas décadas do século $\mathrm{XX}$ seria difícil encontrar alguém que desconhecesse o bordão. Iniciado no rádio, o quadro foi televisionado por trinta e oito anos (entre 1957 e 2000, de maneira intermitente).

Antes da Escolinha do Professor Raimundo, a Escolinha da Professora Olinda foi um conhecido programa de rádio produzido em São Paulo nos anos 1930. Posteriormente, diversos outros projetos humorísticos retrataram jocosamente a relação entre professor/a e estudantes: Escolinha do Golias (SBT 1990 a 1997), Escolinha do Barulho (TV Record 1999 a 2003) e Uma Escolinha Muito Louca (TV Band 2008, ainda em exibição). Tomando a opção pelo termo "escolinha" como um indicador de filiação, seria possível computar mais de 80 anos de longevidade no formato.

Outra genealogia televisiva cujo enredo retrata a vida escolar teve seu ápice com Carrossel. Inspirada em uma novela argentina das décadas de 1960 e 70 (Jacinta Pichimahuida, la maestra que no se olvida), a rede de televisão mexicana Televisa produziu em 1989 uma saga de 375 capítulos apresentando as desventuras vividas por alunos/as da classe de Professora Helena, encenada pela atriz Gabriela Rivero. Carrossel foi transmitido pela primeira vez no Brasil pelo SBT em 
1991, sendo reprisado em 1993, 1995 e $1996^{4}$. Foram realizadas outras tentativas de igualar a popularidade da novela, uma em 1992 com Carrossel das Américas e outra em 2002 com Viva às crianças! Carrossel 2, ambas produzidas pela Televisa e transmitidas pelo SBT. Foi ainda a parceria entre as duas redes que consagrou no Brasil a locução “Tá! Tá! Tá! Tá! Táá!”, interminavelmente repetida pelo Professor Girafales em momentos de irritação. Personagem de Chaves, interpretado por Rubén Aguirre, seus infortúnios docentes são exibidos ininterruptamente no país desde 1984.

O sucesso da escola como entretenimento midiático-comercial pode ser verificado nos filmes sobre high school produzidos por Hollywood. Desde Juventude Transviada (1955) e Grease (1978), passando por Clube dos Cinco (1985) Curtindo a vida adoidado (1986), Karatê Kid (1984), Patricinhas de Beverly Hills (1996), Pânico (1996), American Pie (1999) e As virgens suicidas (1999), até Um amor para recordar (2002), Coach Carter (2005), Escritores da liberdade (2007) e High School Musical (2006) - a lista infindável de filmes no qual a escola tem papel de destaque permite catalogar a produção sobre high school como um gênero cinematográfico específico. Um pouco menos burlescos, mas igualmente significativos são os filmes com viés crítico que propõem leituras "verossímeis", inspiradas na estética de

\footnotetext{
${ }^{4}$ O programa alcançou tal sucesso que, em 1991, Rivero foi recebida pelo então presidente Fernando Collor de Mello em Brasília.
} 
documentários, sobre a educação contemporânea, como as produções francesas Entre os muros da escola (2007) e O dia da saia (2009). Qualquer pessoa que já tenha segurado um controle remoto ou passado os olhos pela programação de cinema certamente recordaria sem esforço outros títulos condizentes.

A intersecção entre escola e entretenimento repercute também nas histórias em quadrinhos. O colégio é tema privilegiado nas tiras da Mafalda (Quino), nas peripécias de Charlie Brown e seus amigos em Peanuts (Charles Schulz), bem como o pesadelo de Calvin em Calvin e Hobbes (Bill Watterson). Se o ambiente escolar não aparece com muita ênfase na Turma da Mônica, certamente é importante no cotidiano rural de Chico Bento (ambos de Maurício de Souza).

A compilação de produções voltadas para o divertimento nas quais abundam representações sobre escola poderia continuar quase indefinidamente. Esta seleção sucinta deve ser suficiente para salientar a relevância da educação formal como matéria prima para o entretenimento. Com ampla circulação social, a abordagem midiática se apropria, alimenta e reformula discursos sobre educação que são cruciais para acessar o imaginário contemporâneo sobre a escola. Implícitas nesse imaginário estão noções específicas sobre os significados de educação, a potencialidade dos processos de ensinoaprendizagem, determinadas apreciações sobre ser professor/a e ser 
estudante, bem como julgamentos acerca das relações geracionais possibilitadas pela convivência escolar.

$\mathrm{O}$ que prontamente se nota em uma tentativa preliminar de compilação é a extrema diversidade de abordagens convivendo em simultâneo. O que chamamos de "mídia" não pode ser encarado como um bloco monolítico, antes comporta profundas diferenças dependendo do contexto de criação, enfoque ideológico e objetivo comercial. Nos interessa questionar como tais diferenças se expressam nas representações sobre escola, sobre as funções docentes e discentes e sobre o conhecimento. Entendidas como discursos, as produções de entretenimento põem em movimento enunciados que cristalizam percepções sobre a escola. Personagens, dilemas, piadas ou dramas que se repetem, se repelem ou se transformam proferem julgamentos sobre educação e sobre a instituição escolar.

Frente à abrangência do objeto, Olhares sobre a escola foi desde sempre pensado como um projeto coletivo e interdisciplinar, composto majoritariamente por estudantes de pedagogia e ciências sociais da UFPR. Trata-se de um exercício de pesquisa que visa ultrapassar os problemas metodológicos de acesso ao público (como se ele estivesse "lá fora") ao criar um ambiente de recepção no qual somos simultaneamente pesquisadores/as. Até o presente, o grupo tem concentrado seus esforços na análise cinematográfica. Essa opção foi em certa medida condicionada pelas facilidades oferecidas no próprio 
formato: um filme é um objeto mais acessível e "compartilhável". Apesar de provisória, a seleção de produções cinematográficas se revelou frutífera e quase inexaurível. Aberto para participação externa no formato Evento de Extensão, realizamos três mostras temáticas: sobre gênero, raça e cultura pop entre 2012 e 2013. A publicação do dossiê temático na Revista Vernáculo se apresenta como uma oportunidade única de reunir produções dispersas e publicizar iniciativas de pesquisa desenvolvidas junto ao Grupo Olhares sobre a escola.

Assim, coube a nós a grata tarefa de apresentar este dossiê que se torna um marco para nosso grupo, uma vez que põe em prática aquilo que há tempos estamos debatendo. E de pronto temos um texto que exemplifica de forma muito clara a proposta constante de construção de uma pesquisa de forma coletiva. O artigo que trata do filme Digam o que quiserem, proposto pelas pesquisadoras Débora Tamires Porcel e Marilene Noriko Treider Otani, expõe em sua essência algo que permeou nossas preocupações: trabalhar com o "não dito cinematográfico". Ou seja, não apenas ver e falar sobre o que o filme aponta, mas também demonstrar de forma crítica aquilo que se encontra nas entrelinhas do fazer fílmico. Lidar com a análise do discurso é algo que demanda uma atenção e dedicação muito mais ampla, e é de onde se pode arrancar o que o filme realmente disse, querendo ou não. É exatamente isso que as autoras conseguem neste artigo. 
O foco do texto no "não dito" textual marca a condução de sua escrita e nos deixa constantemente com uma sensação de que cada frase, cada análise, cada cena, poderia conter em si mais uma dúzia de vieses e diferentes focos, sem assim perder seu poder argumentativo. Apesar do enfoque do artigo ser nas representações de educação e de gênero, ele dá um vislumbre social deveras interessante e singular, e que se expressa de forma simbólica no surgimento de um "novo príncipe", uma nova interpretação de casal cinematográfico.

Em seguida, o/a leitor/a encontrará uma análise marcante sobre o filme Preciosa: uma história de esperança, escrita pela pesquisadora Vanessa Raianna Gelbcke. Inicialmente, a autora traz para o debate o próprio fazer fílmico, destacando duas distintas perspectivas sobre a questão: de que (i) o cinema expressa a realidade e, de outro lado, indicando que (ii) o cinema expressa uma visão de mundo.

A dramática história de Claireece Precius Jones, uma adolescente de 16 anos que mora no Harlem (bairro pobre de Nova Iorque), nos conduz a um ambiente hostil à formação de uma criança. Precius, ou Preciosa - conforme a tradução brasileira -, é agredida física e verbalmente pela mãe e abusada sexualmente pelo pai, com quem teve dois filhos. Distintos estereótipos são enfrentados pela protagonista, sendo mulher, negra, pobre, obesa e mãe solteira na adolescência; nesse contexto, Preciosa transfere-se para um mundo de ilusão. O espaço escolar é retratado como um dos ambientes 
frequentados por Preciosa, contudo, evidencia-se que o sistema escolar tradicional não consegue lidar com a diversidade. Cabe a uma forma alternativa de ensino, destacada pela autora, propiciar um ambiente de acolhimento e diálogo para a emancipação da protagonista de sua realidade conturbada.

Se, por um lado, os artigos anteriores tratam de forma elaborada sobre o diálogo, o textual dos filmes, o artigo que enfoca a produção Aos treze, feito pela pesquisadora Débora Tamires Porcel, tem uma peculiaridade que o torna distinto das demais contribuições. Apesar de ter um olhar para a escrita fílmica ali presente, procura problematizar e enfatizar os aspectos que se apresentam de forma iconográfica. Sendo um objeto que simultaneamente narra (texto) e mostra algo (visual), esse cuidado com os enquadramentos, com o que está na cena, ou o que a cena mostra sem tornar isso dito, é de essencial importância - ainda mais quando o filme em análise trata sobre a juventude e sobre os aspectos ligados a consumo, mas em especial à "beleza". Tendo esses conceitos em vista, e em foco, a apropriação da cena visualmente é quase uma análise hiperbólica do tema. Em função de construções históricas e sociais, a noção de juventude é colocada em questão e nada é mais simbólico do que a análise imagética da mesma, algo que é feito de forma muito madura e elaborada neste texto.

O último artigo, mas não menos importante, problematiza a questão étnico-racial estabelecida nas relações sociais da França. O 
objeto de reflexão é a obra cinematográfica Mon Père est femme de ménage, debatida por Roberto Jardim da Silva. O artigo expressa um grande esforço em contextualizar o cenário social apresentado como pano de fundo para a produção fílmica, neste caso a França. Diferentes fases históricas de processos imigratórios são explicitadas para indicar a configuração étnico-racial francesa. $\mathrm{O}$ espaço geográfico, caracteristicamente periférico, ocupado pelos imigrantes e o estereótipo construído em relação às etnias marginalizadas na sociedade francesa são a base da reflexão teórica do artigo.

Os conflitos raciais estão presentes nas brincadeiras e piadas contadas entre os jovens, problematizadas como uma forma de legitimação do discurso que reforça os estereótipos, naturalizando-os nas relações sociais. Outros elementos da obra fílmica são colocados em evidência, como as questões de gênero e de classe, entrelaçando diferenciadas facetas do mundo social na reflexão teórica. Em meio a isso, a trajetória das distintas etnias representadas no filme (negro, marroquino, judeu, branco) expressa a expectativa estereotipada construída sob o signo racial, delineando um lugar social predestinado a cada etnia-raça na configuração da sociedade francesa.

A seleção de artigos publicados aqui, parte do trabalho contínuo e coletivo do grupo Olhares sobre a escola, explicita a pluralidade de temáticas e reflexões construídas com base na sétima arte, o cinema. Tendo como foco a representação cinematográfica do ambiente escolar 
e/ou da educação, os artigos abrangem, em suas respectivas análises, temáticas comuns ao mundo social contemporâneo. Uma diversidade de questões sociais torna-se parte da reflexão teórica - gênero, etnia/raça, classe, educação. Publicar tais textos representa um passo importante para a consolidação do grupo de pesquisa, expressando a materialização dos esforços desenvolvidos nos últimos anos na UFPR. Esperamos que o/a leitor/a aproveite os artigos a seguir e, caso tenha interesse, participe do grupo que é aberto a diferenciados olhares sobre a escola. 